\title{
Recent Trends in Extreme Precipitation and Temperature over Southeastern South America: The Dominant Role of Stratospheric Ozone Depletion in the CESM Large Ensemble ${ }^{\mathscr{O}}$
}

\author{
YUTIAN WU \\ Department of Earth, Atmospheric and Planetary Sciences, Purdue University, West Lafayette, Indiana \\ LORENZO M. POLVANI \\ Department of Applied Physics and Applied Mathematics, and Department of Earth and Environmental \\ Sciences, Columbia University, New York, New York
}

(Manuscript received 24 February 2017, in final form 18 May 2017)

\begin{abstract}
Observations show an increase in maximum precipitation extremes and a decrease in maximum temperature extremes over southeastern South America (SESA) in the second half of the twentieth century. The Community Earth System Model (CESM) Large Ensemble (LE) experiments are able to successfully reproduce the observed trends of extreme precipitation and temperature over SESA. Careful analysis of a smaller ensemble of CESM-LE single forcing experiments reveals that the trends of extreme precipitation and temperature over SESA are mostly caused by stratospheric ozone depletion. The underlying dynamical mechanism is investigated and it is found that, as a consequence of stratospheric ozone depletion and the resulting southward shift of tropospheric jet streams, anomalous easterly flow and more intense cyclones have occurred over SESA, which are favorable for heavier rainfall extremes and milder heat extremes.
\end{abstract}

\section{Introduction}

Extreme climate events have undoubtedly significant societal and economic impacts. Research into climate extremes has progressed greatly over the last few decades, and numerous efforts have been made to develop datasets of extreme indices across the globe. Several datasets, using different gridding methods and/or input data, indicate large coherent trends in temperature and precipitation extremes over the past few decades. As assessed and summarized in chapter 2 of the Intergovernmental Panel on Climate Change (IPCC) Fifth Assessment Report (AR5), for temperature extremes, "it is very likely that the numbers of cold days and nights have decreased and the numbers of warm days and nights have increased globally since about 1950" (p. 162), and "a large amount of evidence continues to

Supplemental information related to this paper is available at the Journals Online website: http://dx.doi.org/10.1175/ JCLI-D-17-0124.s1.

Corresponding author: Yutian Wu,wu640@purdue.edu support the conclusion that most global land areas analyzed have experienced significant warming of both maximum and minimum temperature extremes since 1950" (Hartmann et al. 2013, p. 209; see also references therein). For precipitation extremes, the same report concluded that "it is likely that since about 1950 the number of heavy precipitation events over land has increased in more regions than it has decreased" (Hartmann et al. 2013, p. 162; see also references therein).

In this study, we focus on southeastern South America (SESA), a region that covers Uruguay, parts of northeastern Argentina, and southern Brazil from $40^{\circ}$ to $25^{\circ} \mathrm{S}$ and from $65^{\circ}$ to $45^{\circ} \mathrm{W}$. In addition to being one of the most densely populated regions in South America, this region of SESA also stands out as a region of great interest for climate change. Specifically, SESA has experienced the largest trend in mean summer rainfall over the twentieth century of the entire world (e.g., Liebmann et al. 2004; Haylock et al. 2006; Barros et al. 2008; Seager et al. 2010). Moreover, for climate extremes, studies have shown that an increase in extreme rainfall events is also most marked in regions such as 
SESA (e.g., Donat et al. 2013; Skansi et al. 2013; also see Figs. 2.33a, 2.33b, and 2.33d of Hartmann et al. 2013). For temperature extremes, although warming trends are found over most of the globe, a significant decrease in warmest days is found over SESA, consistently across various datasets (e.g., Alexander et al. 2006; Rusticucci and Renom 2008; Donat et al. 2013; Skansi et al. 2013; also see Box 2.4, Fig. 1 of Hartmann et al. 2013). The potential driver for these trends, however, remains unclear.

Previous studies have suggested a key role of stratospheric ozone depletion in precipitation trends over SESA. Kang et al. (2011) first attributed the observed mean precipitation increase at southern subtropical latitudes in summer to the formation of the ozone hole. They argued that this occurs via a southward shift of the midlatitude westerly jet and the tropical Hadley cell, resulting in an anomalous rising motion in southern subtropics. A follow-up work of Kang et al. (2013) further suggested that stratospheric ozone depletion likely impacts not only the mean precipitation but also extreme precipitation in Southern Hemisphere in summer. On a regional scale, Gonzalez et al. (2014), focusing on mean precipitation trends over SESA, found the dominance of stratospheric ozone depletion on precipitation increase, consistently across a number of IPCC-class climate models. In contrast, a recent study by Zhang et al. (2016) reported a dominant role of greenhouse gas increase (not stratospheric ozone depletion) on SESA rainfall trends during the twentieth century using Geophysical Fluid Dynamics Laboratory (GFDL) climate model experiments.

In this study, we analyze trends in extreme temperature and precipitation over SESA in the simulations of the Community Earth System Model (CESM) Large Ensemble (LE) Project (Kay et al. 2015). It is now widely recognized that internal climate variability is an important contributor to climate change, especially at regional spatial scales and/or subdecadal to decadal time scales (e.g., Hawkins and Sutton 2009; Deser et al. 2012, 2014), and thus it is inappropriate to compare a single run from any climate models to observations. The CESM-LE Project provides a large number of ensemble runs and thus a unique opportunity to explicitly extract the forced anthropogenic climate change signal from the large internal climate variability, not only for mean climate states but also for climate extremes (e.g., Yoon et al. 2015; Pendergrass et al. 2015; Hagos et al. 2016; Fix et al. 2016; Anderson et al. 2017; Lin et al. 2016; Wang et al. 2016; KirchmeierYoung et al. 2017). The objective of this study is to explore, using CESM-LE single and total forcing experiments, whether anthropogenic forcings have played a role in the observed trends in precipitation and temperature extremes over SESA.

\section{Methods}

For climate extreme indices, we adopt the annual maximum 1-day precipitation amount "Rx1day" and the annual maximum of daily maximum temperature "TXx" to capture extreme precipitation and temperature, respectively. For the observed trends of Rx1day and TXx, we make use of the Hadley Centre extremes dataset (HadEX2), the most comprehensively available global gridded land-based dataset of temperature and precipitation extremes (Donat et al. 2013). Monthly and annual indices are available on a $3.75^{\circ} \times 2.5^{\circ}$ longitudelatitude grid over the period of 1901-2010.

For the numerical experiments, we analyze the CESM-LE Project model output (Kay et al. 2015). All CESM-LE experiments are performed using a single coupled climate model: the CESM version 1 with the Community Atmosphere Model version 5 (CAM5) at approximately $1^{\circ}$ horizontal resolution, coupled with ocean, land, and sea ice components. For the historical simulations, external forcings were specified following phase 5 of the Coupled Model Intercomparison Project (CMIP5) protocol (Lamarque et al. 2010), and ozone concentrations were from the corresponding chemistry climate model (CESM1 Whole Atmosphere Community Climate Model (WACCM); Marsh et al. 2013) forced with surface concentrations of ozone-depleting substances (ODS). There are 42 ensemble members in total for historical experiments, and each member has identical external forcings but is started from slightly perturbed initial conditions in air temperature fields (see Kay et al. 2015).

In this study, we focus on the second half of the twentieth century, specifically the period of 1955-2005, which corresponds to the formation of the ozone hole over the South Pole. We analyze 12 of the historical runs and 12 available single forcing runs that are nearly identical to the historical runs except for the ozone concentrations, which are kept fixed at 1955 levels [see Fig. 2a of England et al. (2016) for the ozone forcing]. These runs are referred to as GHG $\uparrow$ runs since greenhouse gas (GHG) increase is the dominant external forcing. The difference between 12 historical (namely "ALL") and 12 GHG $\uparrow$ runs isolates the effect of stratospheric ozone depletion and is thus referred to as O3 $\downarrow$. The average of 12 ensemble members allows us to extract the forced anthropogenic climate change signal from internal climate variability.

In the CESM-LE experiments, the extreme precipitation index Rx1day is calculated using daily output 
(a) $\operatorname{HadEX} 2$

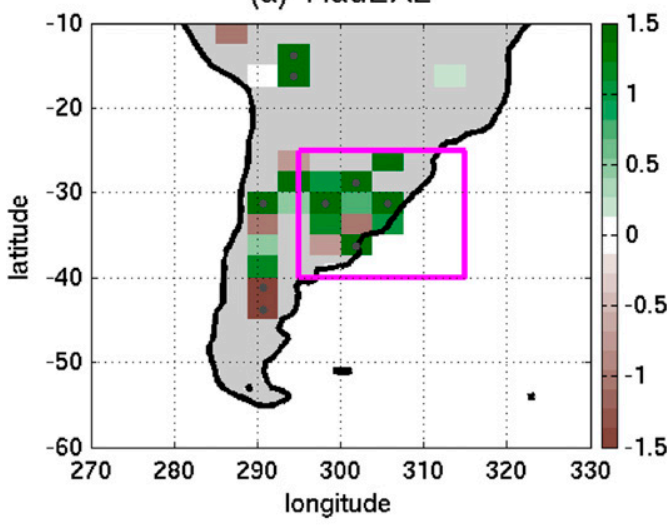

(c) CESM-LE GHG $\uparrow$

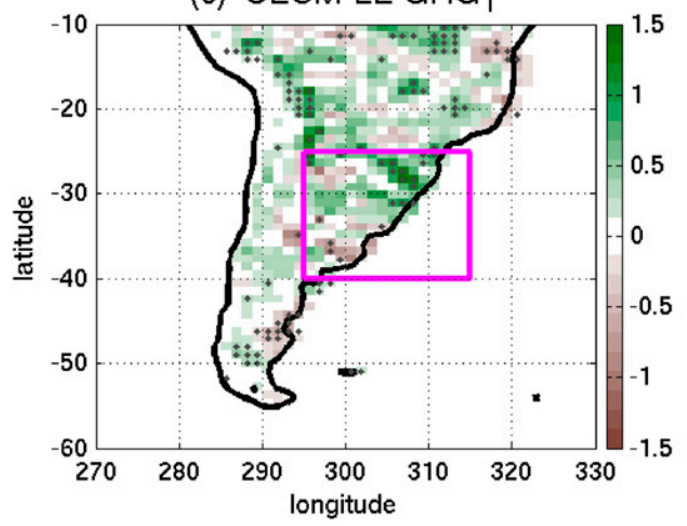

(b) CESM-LE ALL

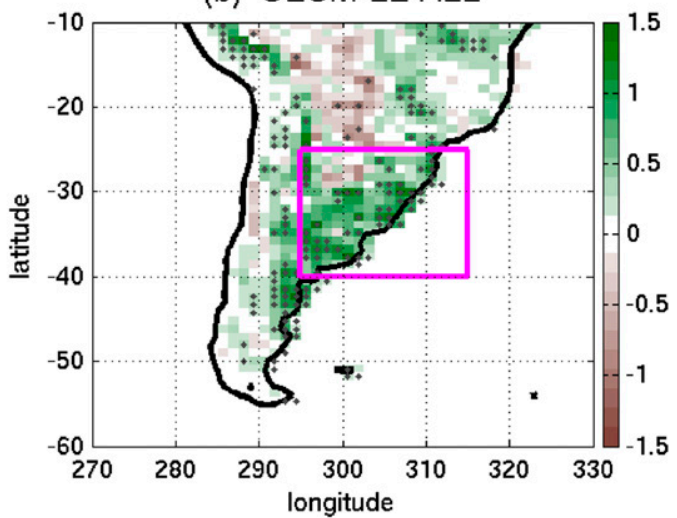

(d) CESM-LE O3\

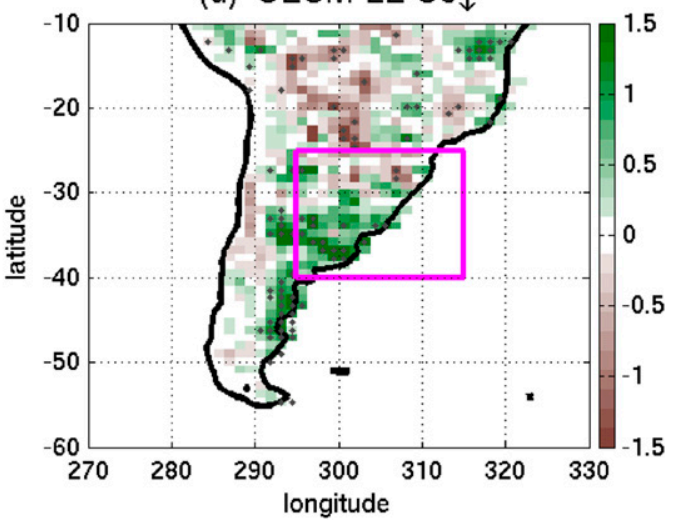

FIG. 1. Trends in annual maximum 1-day precipitation Rx1day ( $\left.\mathrm{mm} \mathrm{day}^{-1} \mathrm{decade}^{-1}\right)$ over the period 1955-2005 in the (a) HadEX2 observation dataset, (b) CESM-LE historical ("ALL") runs, (c) CESM-LE GHG $\uparrow$ runs, and (d) CESM-LE O3 $\downarrow$. Statistically significant trends at the $90 \%$ level are dotted. Pink box highlights the SESA region. Gray areas in (a) indicate insufficient data.

of precipitation (PRECT), and the extreme temperature index TXx is calculated using monthly output of maximum surface temperature (TSMX). To aid the interpretation, daily and monthly zonal and meridional wind at $850 \mathrm{~Pa}$ and monthly vertical velocity at $500 \mathrm{hPa}$ are also used. Unfortunately, daily vertical velocity at $500 \mathrm{hPa}$ was not saved and is only available in two historical runs with no corresponding single forcing runs. In addition, we also use 6-hourly surface temperature output (available during 1990-2005 only) to identify the day when the annual maximum daily maximum temperature occurs.

For both the HadEX2 dataset and the CESM-LE experiments, we focus on the linear trends of annual maximum Rx1day and annual maximum TXx during 1955-2005, the period over which the largest stratospheric ozone depletion occurred over the South Pole. Trends in HadEX2 are calculated only for grid boxes with sufficient data (i.e., at least $66 \%$ of years have data during the period and data are available through at least
2003), following Donat et al. (2013). Statistical significance is evaluated via a simple Student's $t$ test, using the $90 \%$ confidence interval, following the IPCC AR5.

\section{Results}

\section{a. Trends in precipitation and temperature extremes in SESA}

We start by considering precipitation extremes and revisiting the observations. Figure 1a shows an increase in annual maximum 1-day precipitation Rx1day over SESA, of approximately $0.9 \mathrm{~mm} \mathrm{day}^{-1} \mathrm{decade}^{-1}$, over the period 1955-2005 (also see the year-to-year evolution in Fig. S1a in the supplemental material). Similar conclusions of more intense heavy rainfall are also found in other extreme precipitation indices and in other observational datasets (e.g., Donat et al. 2013; Skansi et al. 2013; also see Figs. 2.33a, 2.33b, and 2.33d of Hartmann et al. 2013). This increase in extreme precipitation can 
(a) $\operatorname{HadEX} 2$

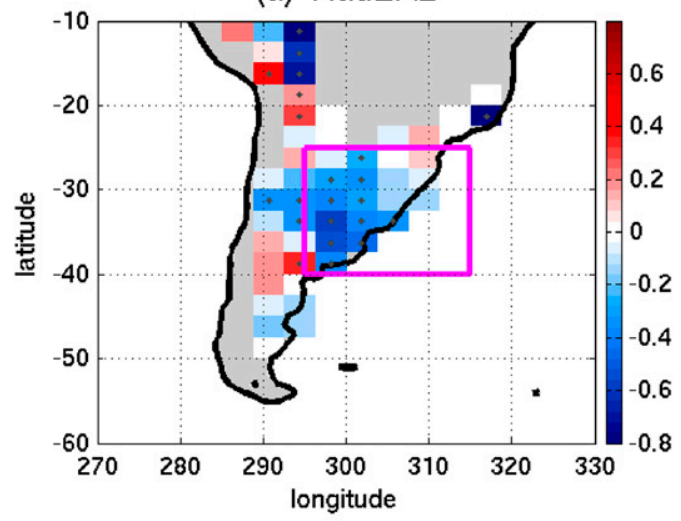

(c) CESM-LE GHG

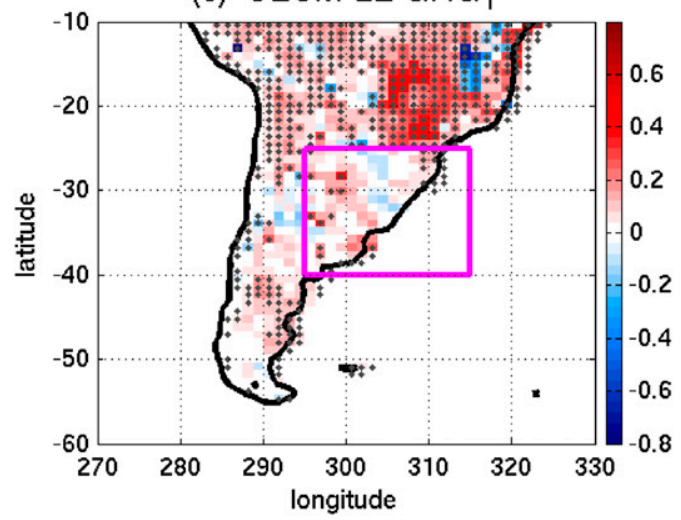

(b) CESM-LE ALL

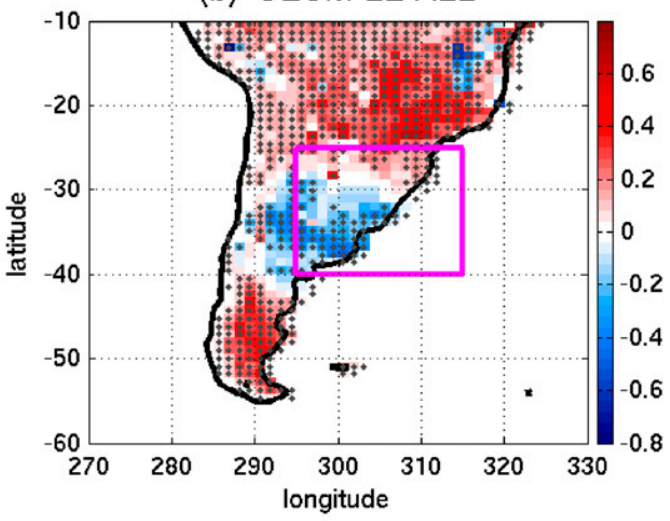

(d) CESM-LE O3\

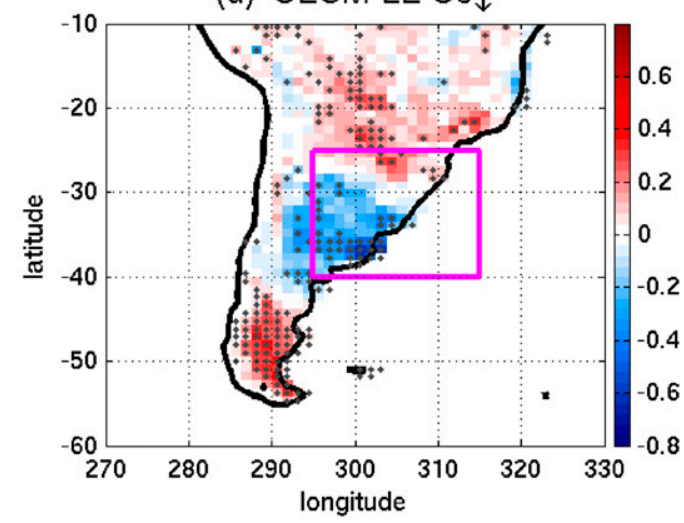

FIG. 2. As in Fig. 1, but for annual maximum of daily maximum surface temperature TXx $\left(\mathrm{Kdecade}^{-1}\right)$.

be captured by the CESM-LE experiments. Figure $1 \mathrm{~b}$ shows the trend of annual maximum Rx1day in the average of 12 historical runs, and a statistically significant increase can be found over most of SESA. The simulated trend averaged over SESA is about $0.69 \mathrm{~mm} \mathrm{day}^{-1}$ decade $^{-1}$ (see Fig. S1b) and is slightly underestimated in the CESM-LE experiments. This increase in extreme precipitation is also found in the average of total 42 historical runs (see Fig. S3a), which suggests the dominance of anthropogenic forcings. Separating the contributions from $\mathrm{GHG} \uparrow$ and $\mathrm{O} 3 \downarrow$, one can see that the increase in extreme precipitation is mostly due to stratospheric ozone depletion, whereas the contribution from GHG increase is minor (cf. Figs. 1c and 1d). About $0.50 \mathrm{~mm} \mathrm{day}^{-1}$ decade $^{-1}$ increase of precipitation extreme over SESA can be attributed to stratospheric ozone depletion while $0.19 \mathrm{~mm} \mathrm{day}^{-1}$ decade $^{-1}$ is due to GHG increase (see Figs. S1b,c).

For temperature extremes over SESA, Fig. 2 shows a decrease in annual maximum daily maximum surface temperature TXx by about $-0.3 \mathrm{~K}$ decade $^{-1}$ (also see Fig. S2a). This cooling trend of maximum extreme temperature has been documented in previous studies (e.g., Alexander et al. 2006; Rusticucci and Renom 2008; Donat et al. 2013; Skansi et al. 2013; also see Box 2.4, Fig. 1 of Hartmann et al. 2013). Figure 2b shows the result from the CESM-LE historical experiments and a similar cooling trend is found (consistent results are also found in 42-ensemble average shown in Fig. S3b). The simulated trend is about $-0.15 \mathrm{Kdecade}^{-1}$ and is underestimated in the model experiments (see Fig. S2b). From the single forcing experiments, it is clear that the decrease in extreme temperature is due to stratospheric ozone depletion, while the GHG increase shows a largely insignificant warming trend (Figs. 2c,d). In the CESM-LE experiments, the stratospheric ozone depletion has led to a decrease of extreme temperature by about $-0.2 \mathrm{~K} \mathrm{decade}^{-1}$, which is slightly compensated by a $0.05 \mathrm{~K} \mathrm{decade}^{-1}$ increase due to GHG increase (see Figs. S2b,c).

\section{b. Dynamical mechanism}

The results of the previous section demonstrate that the depletion of stratospheric ozone has likely led to the observed increase in precipitation extremes while decrease in temperature extremes over SESA in the 
(a) $\zeta 850$ w. Rx1day

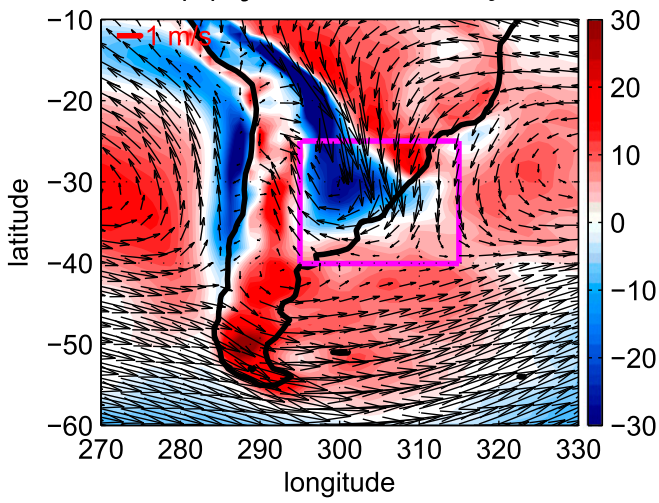

(c) $\zeta 850 \mathrm{w} . \mathrm{TXx}$

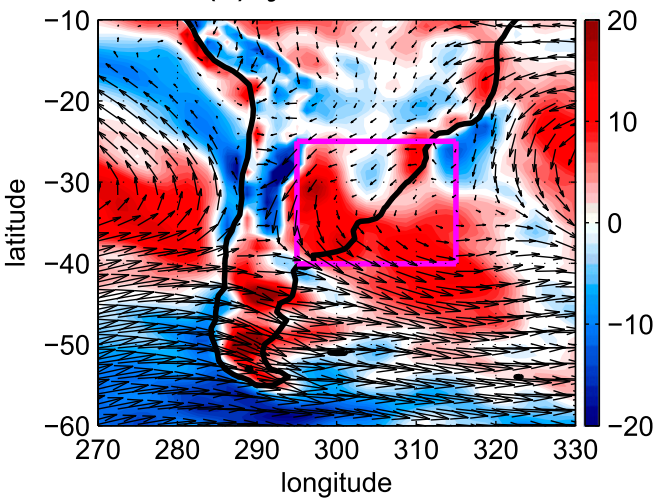

(b) $\omega 500$ w. Rx1day

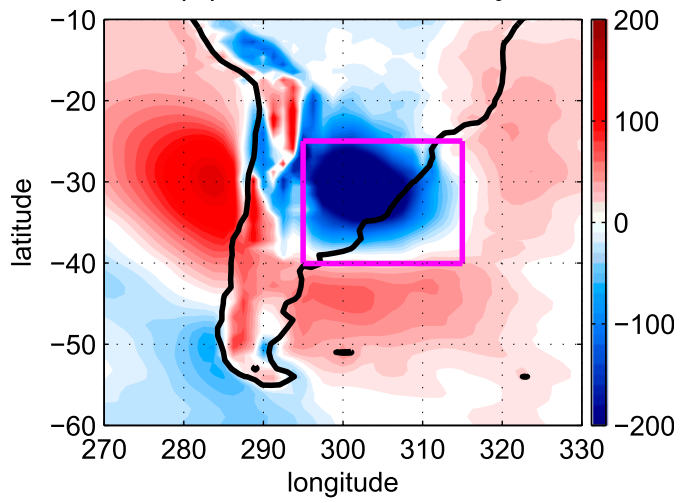

(d) $\omega 500 \mathrm{w} \cdot \mathrm{TXx}$

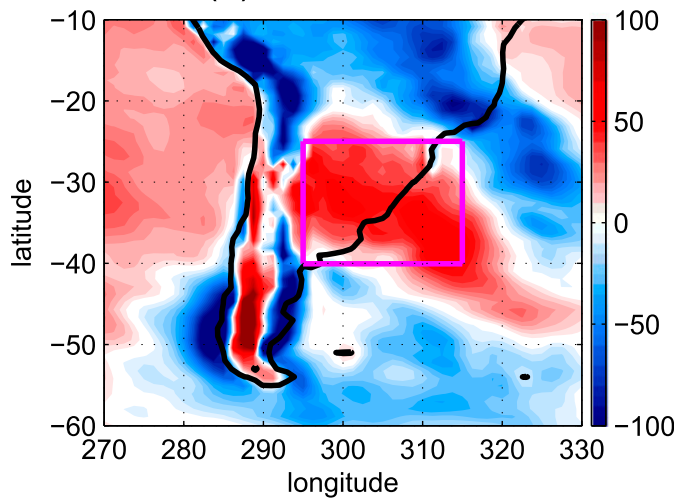

FIG. 3. (a) Composite mean of daily 850 -hPa relative vorticity $\zeta$ (color shading; $\mathrm{s}^{-1}$ ) and daily 850 -hPa horizontal velocity (vectors) during the days of annual maximum 1-day precipitation Rx1day averaged over SESA land in CESM-LE historical runs. The $850-\mathrm{hPa} \zeta$ is scaled by a factor of $10^{6}$. The vectors are plotted at every other longitude and latitude grid point and the arrow scale $\left(1 \mathrm{~m} \mathrm{~s}^{-1}\right)$ is indicated in the top-left corner of (a). (b) As in (a), but for daily 500-hPa vertical velocity $\omega\left(\mathrm{mb}\right.$ day $\left.^{-1}\right)$. (c),(d) As in (a),(b), but for annual maximum daily maximum surface temperature TXx. The results are all statistically significant at the $90 \%$ confidence level. Pink box highlights the SESA region.

second half of the twentieth century. In this section we investigate the dynamical mechanism that is responsible for the trends of extremes from CESM-LE experiments.

We begin by examining what large-scale atmospheric circulation pattern is favorable for annual maximum precipitation and temperature extremes over SESA in the climatology. Figure 3 shows the composite mean of low-level horizontal flow and relative vorticity and vertical velocity during the days of annual maximum 1-day precipitation and annual maximum daily maximum surface temperature, respectively. As can be seen, extreme precipitation over SESA is typically associated with a low-level cyclonic circulation with northerly flow on the northern side of SESA and easterly flow on the southern side (Fig. 3a). This low-level cyclonic circulation and convergence leads to an ascent and generates precipitation (Fig. 3b). Similar results were reported by Martin-Gómez et al. (2016), who found that low-level cyclonic circulation favors the transport of moisture toward SESA in observations. On the contrary, extreme temperature over SESA is accompanied by a low-level anticyclone and descent (Figs. 3c,d). Because of that, there is an anticorrelation between annual precipitation extremes and annual temperature extremes over SESA (not shown).

Next we examine how the atmospheric circulation has changed during 1955-2005. Because of the lack of daily output of vertical velocity in most of CESM-LE experiments, we first consider the trends in monthly circulation, specifically during October-March (ONDJFM) when most precipitation and temperature extremes occur over SESA (not shown). Figures $4 a$ and $4 b$ show the trend of monthly low-level circulation and vertical velocity, respectively, in historical runs. As can be seen, the trends consist of an easterly flow, low-level cyclonic circulation with convergence, and ascent over SESA. 
(a) $\zeta 850$ trend ALL

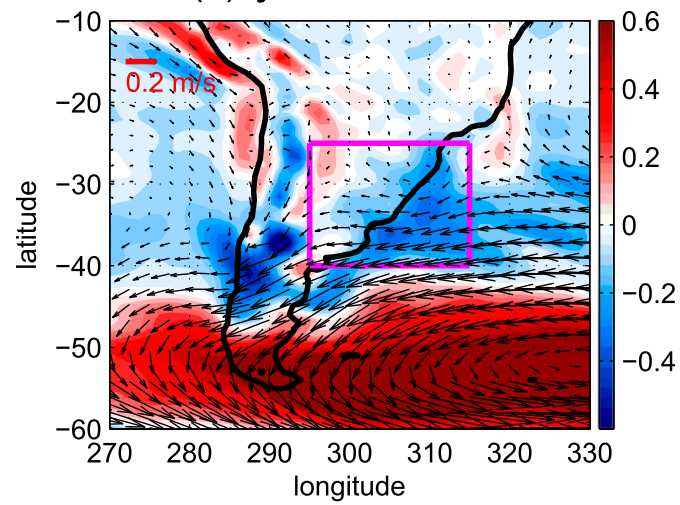

(c) $\zeta 850$ trend $\mathrm{GHG} \uparrow$

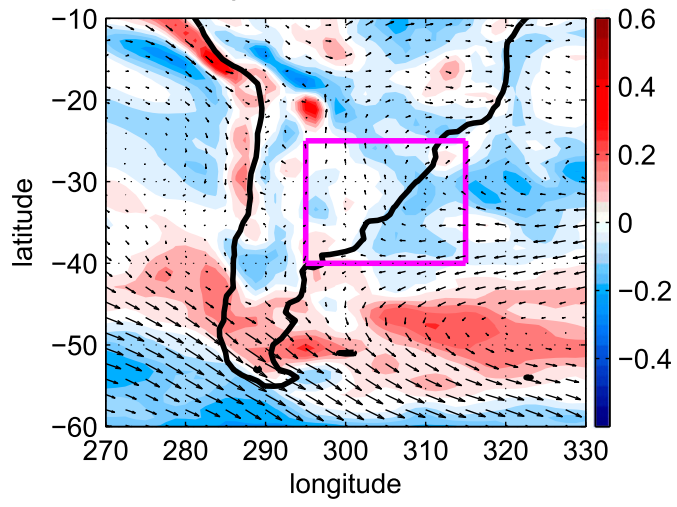

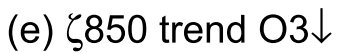

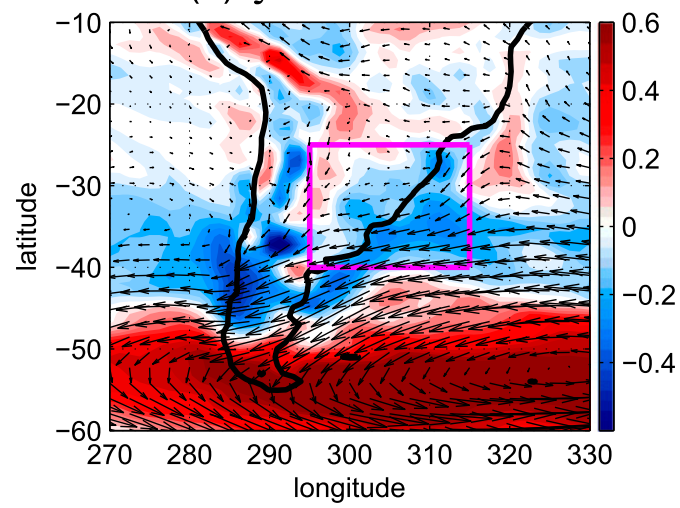

(b) $\omega 500$ trend ALL

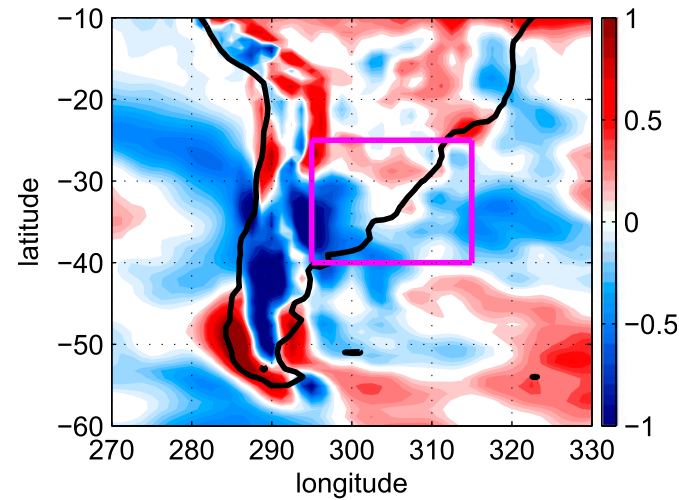

(d) $\omega 500$ trend $\mathrm{GHG} \uparrow$

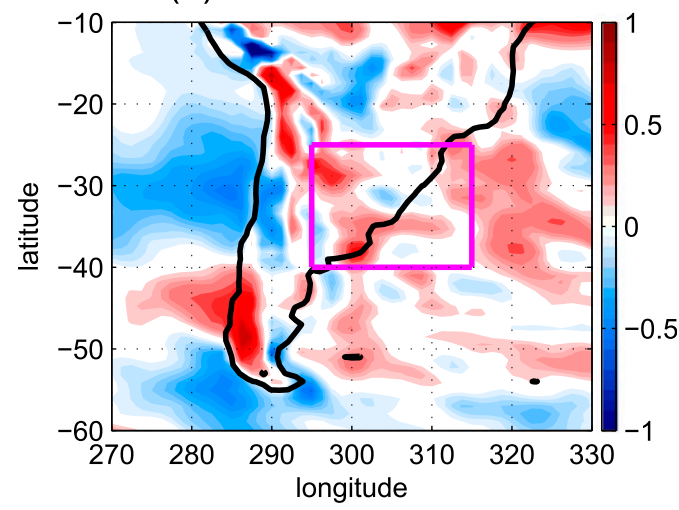

(f) $\omega 500$ trend $03 \downarrow$

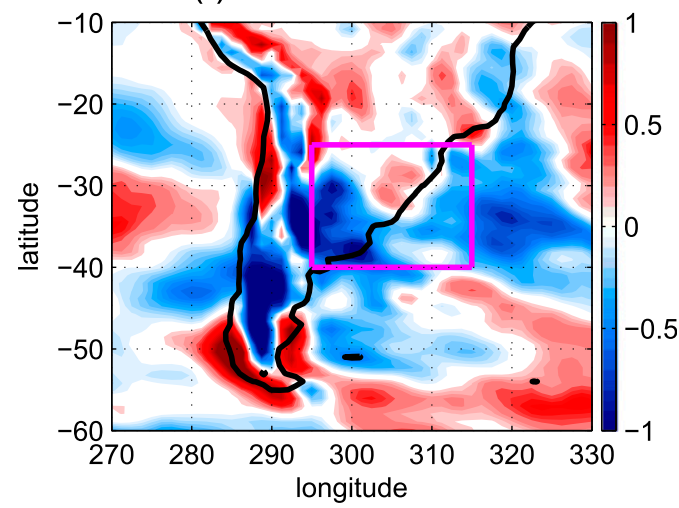

FIG. 4. Trends in monthly 850 -hPa relative vorticity $\zeta$ (color shading; $\mathrm{s}^{-1}$ decade $^{-1}$ ) and monthly 850 -hPa horizontal velocity (vectors) during October-March (ONDJFM) in CESM-LE (a) historical runs, (c) GHG $\uparrow$ runs, and (e) $\mathrm{O} 3 \downarrow$. Trends in $850-\mathrm{hPa} \zeta$ are scaled by a factor of $10^{6}$. The vectors are plotted at every other longitude and latitude grid point and the arrow scale $\left(0.2 \mathrm{~m} \mathrm{~s}^{-1}\right)$ is indicated in the top-left corner of (a). (b),(d),(f) As in (a),(c),(e), but for trends in monthly 500-hPa vertical velocity $\left(\mathrm{mb} \mathrm{day}^{-1}\right.$ decade $\left.^{-1}\right)$. The results are all statistically significant at the $90 \%$ confidence level.

This trend of circulation is mostly due to stratospheric ozone depletion, whereas in GHG $\uparrow$ runs there is a smaller trend of low-level circulation and a small trend of descent (contrast the middle and bottom panels of Fig. 4). Figure S4 shows the monthly trend of surface temperature indicating a cooling trend in parts of SESA, in agreement with observations (e.g., de Barros Soares et al. 2017). This cooling trend is again due to stratospheric ozone depletion (Fig. S4c). The dominance of stratospheric ozone depletion on the Southern 
(a) SESA $\zeta 850$ ALL

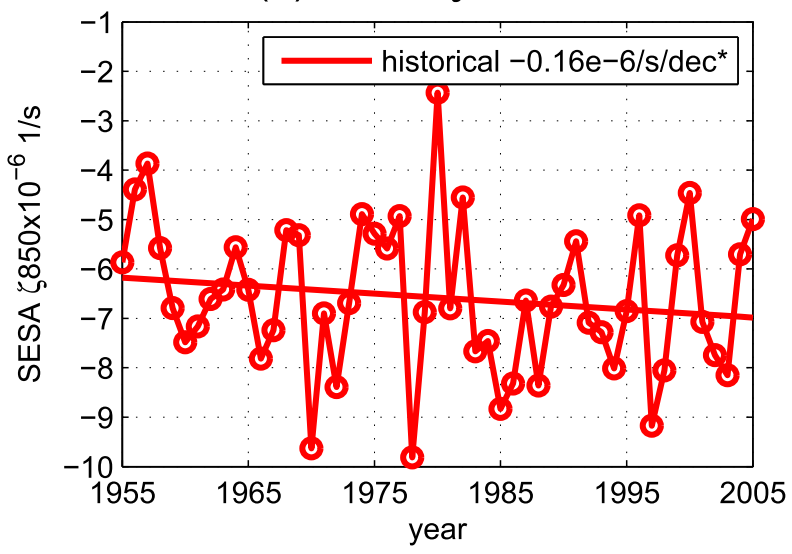

(b) GHG $\uparrow$

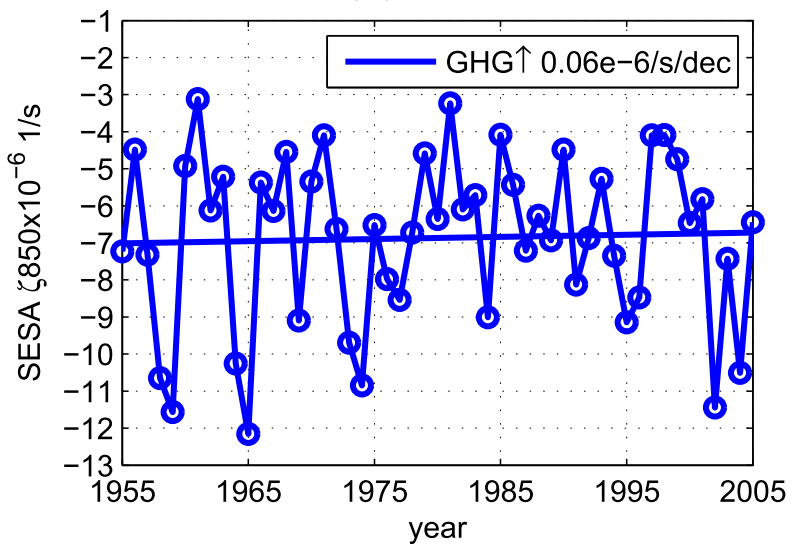

FIG. 5. SESA $850-\mathrm{hPa}$ relative vorticity $\zeta$ evaluated during the days of annual maximum 1-day precipitation over SESA land. The results are shown for the average of (a) 12 CESM-LE historical (red) and (b) 12 CESM-LE GHG $\uparrow$ runs (blue). The linear trend is $-0.16 \times 10^{-6} \mathrm{~s}^{-1}$ decade $^{-1}$ for historical runs and $0.06 \times$ $10^{-6} \mathrm{~s}^{-1}$ decade $^{-1}$ for $\mathrm{GHG} \uparrow$ runs, as indicated in the legend. An asterisk is added to the legend if the linear trend is statistically significant at the $90 \%$ level.

Hemisphere circulation trend has been widely studied in previous work [see the review papers by Thompson et al. (2011) and Previdi and Polvani (2014), and references therein]. The depletion of stratospheric ozone, due to increase of human-made ODS, has led to a cooling of the polar stratosphere, a strengthening of the stratospheric polar vortex, and a southward shift of the tropospheric jet stream. This southward shift of the tropospheric jet can be seen in Figs. $4 \mathrm{a}$ and $4 \mathrm{e}$, where westerly anomalies are found southward of $55^{\circ} \mathrm{S}$ and easterly anomalies between $30^{\circ}$ and $55^{\circ} \mathrm{S}$. It is the low-level easterly anomaly over SESA that leads to more horizontal convergence, increased ascent and, ultimately, greater precipitation.

More importantly, this trend toward more easterly flow and low-level cyclonic circulation and ascent also occurs at daily time scale and causes stronger intense precipitation extremes and less intense temperature extremes. To show that, we use daily low-level relative vorticity $\zeta$ to illustrate the intensity of low-level cyclone (as daily vertical velocity output is not available). Figure 5 shows the SESA low-level $\zeta$ evaluated during the days of annual maximum 1-day precipitation in both historical and GHG $\uparrow$ runs. For the historical runs, one can see a statistically significant decline in $\zeta$ (by about $13 \%$ during 1955-2005), suggesting an increase in low-level cyclone intensity that favors stronger intense rainfall extremes and less intense heat extremes. In the GHG $\uparrow$ runs, however, the trend is much smaller and is insignificant. This confirms that, as found in the CESMLE experiments, it is the stratospheric ozone depletion that causes anomalous low-level easterly flow and more intense cyclones over SESA, leading to heavier rainfall extremes while milder heat extremes in the latter half of the twentieth century.

\section{Summary and discussion}

Using the CESM-LE experiments, we have demonstrated that stratospheric ozone depletion has caused an increase in extreme precipitation and a decrease in extreme temperature over SESA in the second half of the twentieth century. The mechanism works via changes in large-scale atmospheric circulation: as a result of lower stratospheric cooling accompanying the ozone hole and a southward shift of the tropospheric jet, anomalous easterly flow and more intense cyclones are induced over SESA, and these are favorable for heavier rainfall extremes and milder high temperature extremes. This study adds to the existing literature and explicitly demonstrates the impact of stratospheric ozone depletion on not only mean climate states but also climate extremes.

As for the relative importance of anthropogenic forcing and internal variability, Fig. S5 shows the range of trends in the CESM-LE preindustrial integration and 12-member historical experiments. The range of trends in the preindustrial integration is obtained by computing all consecutive and overlapping 51-yr trends throughout the entire 1700 -yr-long integration. It is found that, first, for both temperature and precipitation extreme indices, both the observed trend and the averaged trend of the 12-member historical runs lie within the trend distribution of the preindustrial integration. However, the trend distributions of the historical runs and preindustrial integration are statistically significantly different at the $95 \%$ confidence level. This suggests that, with anthropogenic forcing, particularly stratospheric ozone depletion in this case, the likelihood of heavier precipitation 
extremes and milder high temperature extremes over SESA is significantly increased.

Our results are in agreement with the multimodel analysis of Gonzalez et al. (2014) but are in contrast to the findings of Zhang et al. (2016). The discrepancy could be due to the following factors. First, Zhang et al. (2016) used the GFDL model, which might have different sensitivity to ozone forcing and greenhouse gas increase. Second, there are differences in the ozone forcings and the time periods considered. Zhang et al. (2016) used the observed ozone concentrations and focused on the precipitation trend over the entire twentieth century whereas we use the ozone concentrations calculated from the CESM1-WACCM and focus on the period of 1955-2005. As demonstrated in Waugh et al. (2015), it is important to examine the impact of stratospheric ozone depletion over the period when ozone hole was formed (the second half of the twentieth century). Third, different numbers of ensemble runs are analyzed. Zhang et al. (2016) used a 3-member ensemble, whereas our study is based on a 12-member ensemble.

There is a body of literature on the detection, attribution, and mechanism of temperature and precipitation extremes, and they have greatly advanced our understanding. However, most climate extreme studies have focused on GHG increase and its impacts on precipitation and temperature from the perspective of thermodynamics (e.g., O'Gorman and Schneider 2009; Fischer et al. 2013; O'Gorman 2015; Donat et al. 2016; Fischer and Knutti 2016). Our study clearly demonstrates that large-scale atmospheric circulation changes can also significantly affect precipitation and temperature extremes, and should be taken into consideration.

Finally, the results of this paper imply that predictions of future trends in precipitation and temperature extremes over SESA are highly uncertain. On the one hand, increasing GHG will force warmer surface temperature, and its thermodynamic impact on trends in extremes will likely be significant. On the other hand, as we have shown here, trends in extremes over SESA have been largely controlled by trends in atmospheric circulation, not surface temperature, in the second half of the twentieth century. And, as demonstrated in the wide literature (e.g., Barnes et al. 2014; Wu and Polvani 2015), the recovery of stratospheric ozone in coming decades will largely cancel the GHG-induced trends in atmospheric circulation and hydrological cycle in the Southern Hemisphere. Hence, it is conceivable that the recently observed trends in precipitation and temperature extremes over SESA would also be cancelled in coming decades, and GHG-induced trends will not appear until late in this century. Therefore, more work is needed to carefully examine the relative contributions of the thermodynamic and dynamical mechanisms in determining the future trends in extremes over SESA.

Acknowledgments. The computations were carried out with high-performance computing support provided by NCAR's Computational and Information Systems Laboratory, which is sponsored by the National Science Foundation. The data produced for and analyzed in this paper are archived on the High Performance Storage System (HPSS) at the National Center for Atmospheric Research and can be provided upon request. YW is funded by Grant AGS-1406962 from the National Science Foundation (NSF) to Purdue University. LMP is funded by Grant AGS-1322439 from the NSF to Columbia University.

\section{REFERENCES}

Alexander, L. V., and Coauthors, 2006: Global observed changes in daily climate extremes of temperature and precipitation. J. Geophys. Res., 111, D05109, doi:10.1029/2005JD006290.

Anderson, G. B., K. W. Oleson, B. Jones, and R. D. Peng, 2017: Projected trends in high-mortality heatwaves under different scenarios of climate, population, and adaptation in 82 US communities. Climatic Change, doi:10.1007/s10584-016-1779-x, in press.

Barnes, E. A., N. W. Barnes, and L. M. Polvani, 2014: Delayed Southern Hemisphere climate change induced by stratospheric ozone recovery, as projected by the CMIP5 models. J. Climate, 27, 852-867, doi:10.1175/JCLI-D-13-00246.1.

Barros, V. R., M. E. Doyle, and I. A. Camilloni, 2008: Precipitation trends in southeastern South America: Relationship with ENSO phases and with low-level circulation. Theor. Appl. Climatol., 93, 19-33, doi:10.1007/s00704-007-0329-x.

de Barros Soares, D., H. Lee, P. C. Loikith, A. Barkhordarian, and C. R. Mechoso, 2017: Can significant trends be detected in surface air temperature and precipitation over South America in recent decades? Int. J. Climatol., 37, 1483-1493, doi:10.1002/ joc. 4792 .

Deser, C., R. Knutti, S. Solomon, and A. S. Phillips, 2012: Communication of the role of natural variability in future North American climate. Nat. Climate Change, 2, 775-779, doi:10.1038/nclimate1562.

_ A. S. Phillips, M. A. Alexander, and B. V. Smoliak, 2014: Projecting North American climate over the next 50 years: Uncertainty due to internal variability. J. Climate, 27, 22712296, doi:10.1175/JCLI-D-13-00451.1.

Donat, M. G., and Coauthors, 2013: Updated analyses of temperature and precipitation extreme indices since the beginning of the twentieth century: The HadEX2 dataset. J. Geophys. Res. Atmos., 118, 2098-2118, doi:10.1002/jgrd.50150.

—, A. L. Lowry, L. V. Alexander, P. A. O'Gorman, and N. Maher, 2016: More extreme precipitation in the world's dry and wet regions. Nat. Climate Change, 6, 508-513, doi:10.1038/ nclimate2941.

England, M. R., L. M. Polvani, K. L. Smith, L. Landrum, and M. M. Holland, 2016: Robust response of the Amundsen Sea low to stratospheric ozone depletion. Geophys. Res. Lett., 43, 82078213, doi:10.1002/2016GL070055.

Fischer, E. M., and R. Knutti, 2016: Observed heavy precipitation increase confirms theory and early models. Nat. Climate Change, 6, 986-991, doi:10.1038/nclimate3110. 
_ - U. Beyerle, and R. Knutti, 2013: Robust spatially aggregated projections of climate extremes. Nat. Climate Change, 3, 1033 1038, doi:10.1038/nclimate2051.

Fix, M. J., D. Cooley, S. R. Sain, and C. Tebaldi, 2017: A comparison of U.S. precipitation extremes under RCP8.5 and RCP4.5 with an application of pattern scaling. Climatic Change, doi:10.1007/s10584-016-1656-7, in press.

Gonzalez, P., L. Polvani, R. Seager, and G. Correa, 2014: Stratospheric ozone depletion: A key driver of recent precipitation trends in south eastern South America. Climate Dyn., 42, 1775-1792, doi:10.1007/s00382-013-1777-x.

Hagos, S. M., L. R. Leung, J.-H. Yoon, J. Lu, and Y. Gao, 2016: A projection of changes in landfalling atmospheric river frequency and extreme precipitation over western North America from the Large Ensemble CESM simulations. Geophys. Res. Lett., 43, 1357-1363, doi:10.1002/2015GL067392.

Hartmann, D. L., and Coauthors, 2013: Observations: Atmosphere and surface. Climate Change 2013: The Physical Science Basis, T. F. Stocker et al., Eds., Cambridge University Press, 159254.

Hawkins, E., and R. Sutton, 2009: The potential to narrow uncertainty in regional climate predictions. Bull. Amer. Meteor. Soc., 90, 1095-1107, doi:10.1175/2009BAMS2607.1.

Haylock, M., and Coauthors, 2006: Trends in total and extreme South American rainfall in 1960-2000 and links with sea surface temperature. J. Climate, 19, 1490-1512, doi:10.1175/ JCLI3695.1.

Kang, S. M., L. M. Polvani, J. C. Fyfe, and M. Sigmond, 2011: Impact of polar ozone depletion on subtropical precipitation. Science, 332, 951-954, doi:10.1126/science.1202131.

,,,--- S.-W. Son, M. Sigmond, and G. J. P. Correa, 2013: Modeling evidence that ozone depletion has impacted extreme precipitation in the austral summer. Geophys. Res. Lett., 40, 4054-4059, doi:10.1002/grl.50769.

Kay, J. E., and Coauthors, 2015: The Community Earth System Model (CESM) Large Ensemble Project: A community resource for studying climate change in the presence of internal climate variability. Bull. Amer. Meteor. Soc., 96, 1333-1349, doi:10.1175/BAMS-D-13-00255.1.

Kirchmeier-Young, M., F. Zwiers, and N. Gillett, 2017: Attribution of extreme events in Arctic sea ice extent. J. Climate, 30, 553571, doi:10.1175/JCLI-D-16-0412.1.

Lamarque, J.-F., and Coauthors, 2010: Historical (1850-2000) gridded anthropogenic and biomass burning emissions of reactive gases and aerosols: Methodology and application. Atmos. Chem. Phys., 10, 7017-7039, doi:10.5194/ acp-10-7017-2010.

Liebmann, B., and Coauthors, 2004: An observed trend in central South American precipitation. J. Climate, 17, 4357-4367, doi:10.1175/3205.1.

Lin, L., Z. Wang, Y. Xu, and Q. Fu, 2016: Sensitivity of precipitation extremes to radiative forcing of greenhouse gases and aerosols. Geophys. Res. Lett., 43, 9860-9868, doi:10.1002/ 2016GL070869.

Marsh, D. R., M. J. Mills, D. E. Kinnison, J.-F. Lamarque, N. Calvo, and L. M. Polvani, 2013: Climate change from 1850 to 2005 simulated in CESM1(WACCM). J. Climate, 26, 73727391, doi:10.1175/JCLI-D-12-00558.1.

Martin-Gómez, V., E. Hernández-Garcia, M. Barreiro, and C. López, 2016: Interdecadal variability of southeastern South America rainfall and moisture sources during the austral summertime. J. Climate, 29, 6751-6763, doi:10.1175/ JCLI-D-15-0803.1.

O'Gorman, P. A., 2015: Precipitation extremes under climate change. Curr. Climate Change Rep., 1, 49-59, doi:10.1007/ s40641-015-0009-3.

, and T. Schneider, 2009: The physical basis for increases in precipitation extremes in simulations of 21st-century climate change. Proc. Natl. Acad. Sci. USA, 106, 14773-14777, doi:10.1073/pnas.0907610106.

Pendergrass, A. G., F. Lehner, B. M. Sanderson, and Y. Xu, 2015: Does extreme precipitation intensity depend on the emissions scenario? Geophys. Res. Lett., 42, 8767-8774, doi:10.1002/ 2015 GL065854.

Previdi, M., and L. M. Polvani, 2014: Climate system response to stratospheric ozone depletion and recovery. Quart. J. Roy. Meteor. Soc., 140, 2401-2419, doi:10.1002/qj.2330.

Rusticucci, M., and M. Renom, 2008: Variability and trends in indices of quality-controlled daily temperature extremes in Uruguay. Int. J. Climatol., 28, 1083-1095, doi:10.1002/joc.1607.

Seager, R., N. Naik, W. Baethgen, A. Robertson, Y. Kushnir, J. Nakamura, and S. Jurburg, 2010: Tropical oceanic causes of interannual to multidecadal precipitation variability in southeast South America over the past century. J. Climate, 23, 5517-5539, doi:10.1175/2010JCLI3578.1.

Skansi, M., and Coauthors, 2013: Warming and wetting signals emerging from analysis of changes in climate extreme indices over South America. Global Planet. Change, 100, 295-307, doi:10.1016/j.gloplacha.2012.11.004.

Thompson, D. W. J., S. Solomon, P. J. Kushner, M. H. England, K. M. Grise, and D. J. Karoly, 2011: Signatures of the Antarctic ozone hole in Southern Hemisphere surface climate change. Nat. Geosci., 4, 741-749, doi:10.1038/ngeo1296.

Wang, Z., L. Lin, M. Yang, and Y. Xu, 2016: The effect of future reduction in aerosol emissions on climate extremes in China. Climate Dyn., 47, 2885-2899, doi:10.1007/s00382-016-3003-0.

Waugh, D. W., C. I. Garfinkel, and L. M. Polvani, 2015: Drivers of the recent tropical expansion in the Southern Hemisphere: Changing SSTs or ozone depletion? J. Climate, 28, 6581-6586, doi:10.1175/JCLI-D-15-0138.1.

Wu, Y., and L. M. Polvani, 2015: Contrasting short- and long-term projections of the hydrological cycle in the southern extratropics. J. Climate, 28, 5845-5856, doi:10.1175/ JCLI-D-15-0040.1.

Yoon, J.-H., S.-Y. S. Wang, R. R. Gillies, B. Kravitz, L. Hipps, and P. J. Rasch, 2015: Increasing water cycle extremes in California and in relation to ENSO cycle under global warming. Nat. Commun., 6, 8657, doi:10.1038/ncomms9657.

Zhang, H., T. Delworth, F. Zeng, G. Vecchi, K. Paffendorf, and L. Jia, 2016: Detection, attribution, and projection of regional rainfall changes on (multi-)decadal time scales: A focus on southeastern South America. J. Climate, 29, 8515-8534, doi:10.1175/JCLI-D-16-0287.1. 